\title{
Environmental impact assessment of flood mitigation measures: methodology based on risk analysis
}

\author{
M Zeleňáková \& L. Zvijáková \\ Institute of Environmental Engineering, \\ Technical University of Košice, Slovakia
}

\begin{abstract}
Environmental impact assessment (EIA) is a process with several important purposes, the principal of which is to be an aid to decision-making; providing decision-makers with a focused evaluation of the likely environmental consequences of sanctioning a proposed development action, before a decision is taken and at a time where it can actually affect the outcome. Risk analysis (RA) has become in recent years an important tool for decision-making and management activities. The objective of the paper is to propose a methodology for assessing water constructions, which will allow the assessment impact of water constructions on the environment and hence select the best option for the permission process. This methodology is intended to streamline the process of EIA of constructions in the field of water management. One of the paper's objectives is to create a system of EIA of water constructions through RA evaluation of options, the result of which should lead to the selection of future activity, quantified with minimum risk to the environment. Comparison options and the designation of the optimal variant will be implemented based on selected criteria which objectively describe the characteristic lines of the planned variants and their impact on the environment. The application of developed methodology for the process of EIA will develop assumptions for further improvements and, respectively, more effective implementation and performance of this process.

Keywords: environmental impact assessment, risk analysis, flood protection measures.
\end{abstract}




\section{Introduction}

EIA has a strong legislative basis, beginning in the United States with the National Environmental Policy Act of 1969 (NEPA). At present in the European Union, the EIA Directive (2011/92/EU) requires that certain developments be assessed for likely environmental effects before planning permission can be granted. At present in Slovakia, Law No. 408/2011 Coll., amending and supplementing Law No. 24/2006 Coll. on the assessment of environmental impacts [1], has been effective from 1st December 2011 (Fig. 1).

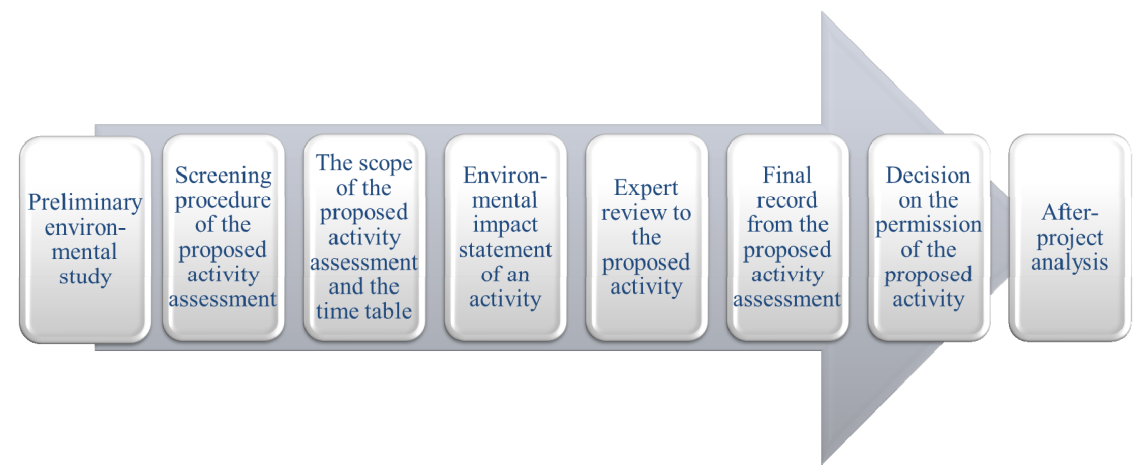

Figure 1: Scheme of EIA procedure in Slovakia.

EIA is a process with several important purposes, the principal of which is to be an aid to decision-making; providing decision-makers with a focused evaluation of the likely environmental consequences of sanctioning a proposed development action, before a decision is taken and at a time where it can actually affect the outcome.

To support decision-making on design and operation, risk analyses are conducted. The analyses include identification of hazards and threats, cause analyses, consequence analyses and risk description. The results of the analyses are then evaluated (Aven [2]). At present, risk analysis is being used to evaluate and manage the potential of unwanted circumstances in a large array of areas: industrial explosions; machine part and other mechanical and process failures; workplace injuries; injury or death from diseases, natural causes, lifestyles, and voluntarily pursued activities; the impacts of economic development on ecosystems; and financial market transactions (among others, Boroush [3]).

The exploration of risk analysis is essential both theoretically and practically as it reduces the risk of loss, venturesome dealings and harm for a company's good will. The shortage of both theoretical and practical knowledge about risk, processes of risk analysis and its stages prevent companies from business development both locally and internationally. The exploration of this field is even more relevant because there is no clear and unanimous concept of risk analysis which would be accepted both by scientists and the business environment (Startienè and Remeikienè [4]). 
The totality of the analyses and the evaluations are referred to as risk assessment (Aven [2]). In a risk assessment, the aim is to uncover all relevant consequences, then assess uncertainties and assign probabilities (Aven et al. [5]).

Risk assessment provides a basis for Aven [2]:

- Choosing between various alternative solutions and activities while in the planning phase of a system.

- Choosing between alternative designs of a solution or a measure.

- Drawing conclusions on whether specific solutions and measures meet stated requirements.

- Setting requirements for various solutions and measures; for example, related to the performance of the preparedness systems.

- Documenting an acceptable safety and risk level.

Risk assessment is followed by risk management, which is a process involving the development and implementation of measures to modify risk, including measures designed to avoid, reduce ("optimize"), transfer or retain risk (Zvijáková [6]). Risk management is defined as all measures and activities carried out to manage risk (Karelová et al. [7]). Risk management deals with balancing the conflicts inherent in exploring opportunities on the one hand, and avoiding losses, accidents, and disasters on the other.

Risk analysis has become in recent years an important tool for decisionmaking and management activities (Gałaś and Gałaś [8]). The aim of the paper is to develop a general methodology for the analysis and evaluation of environmental impacts of actions in water management by using a risk analysis method. The application of a developed methodology for the process of EIA will develop assumptions for further improvements, respectively, and more effective implementation and performance of this process.

\section{Material and methods}

The paper presents the new scientific approach of using risk analysis in the performance of EIA methodologies. The basic principle of the proposed action is to calculate the risk index - an estimation of the level of risk posed by the proposed activity on the environment. Risk analysis is based on the principle that the proposed activity is related to stressors that present the risk for the environment. This can be quantified by calculating the individual risk for each identified stressor's effects on components of the environment. In total, it is possible to calculate the overall risk which the proposed activity poses to the environment and human health (Zvijáková [6]). Risk analysis includes the following objectives and tasks.

The aim of the first objective is to identify sources of risk areas and their impact on the various components of the environment, including the inhabitants, based on the modified method of risk analysis - UMRA. It includes the following tasks.

- Identification of sources of risk - stressors - to identify pollutants or activities that alter the natural environment as a result of the planned activities. 
- Definition of areas of impact - environmental components, which may be influenced by activity - population, rock, minerals, geodynamic phenomena and geomorphological conditions, climatic conditions, air, water conditions, soil, flora, fauna and their habitats; country - the structure and land use, landscape painting, protected areas and their buffer zones; territorial system of ecological stability; urban environment and land use, cultural and historical heritage, cultural and historical values, archaeological and paleontological sites and important geological sites and other effects.

- Identification of the environmental impacts of stressors by the UMRA to identify and record potential risks - a stressor which has an effect on components of the environment by marking the box in UMRA.

Prediction of impacts is the second objective which is described as a string of probabilities and consequences of a stressor on environmental components (Gałaś et al. [9]). It involves three tasks.

- Creation of sets of criteria in order to predict effects; it is necessary to propose a set of criteria that reflect the impact of the proposed activity on the environment.

- Determination of the likelihood of adverse effects from exposure of stressors to environmental components - to determine the value of the likelihood " $\mathrm{Li}$ ", four levels were chosen $(0.25$ - can occur only in very exceptional cases; 0.50 - could happen in some cases; 0.75 - is likely to occur in many cases; 1 - it is expected that it will occur in most cases).

- Determination of consequences after exposure to a negative stressor on the individual components of the environment - to determine the value of the consequence " $C_{\mathrm{i}}$ ", four levels were chosen $(0.25$ - at least one marginal or no damage except for a few individuals/populations who may require first aid; 0.50 - small or no degradation of the environment; 0.75 - medium damage of some individuals/populations who may require medical attention; 1 - large disturbance of biological communities that is reversible and limited in time and space, or the number of affected individuals/populations it is expected there will be in most cases).

Assessment of potential impacts of the activity on the environment is the last objective and the most important step in the EIA process (Zeleňáková and Zvijáková [10]). The aim is to assess the significance of environmental changes which may result from the proposed activity. The task is to determine the level of risk, which arises from the action of each stressor on the individual components of the environment as a consequence of the activity.

- Calculation of risk $R_{\mathrm{i}}-$ according to equation (1):

$$
R_{i}=L_{i} \cdot C_{i}
$$

where $\quad R_{\mathrm{i}}=$ individual risk of each stressor impact on the compound of the environment;

$$
\begin{aligned}
& L_{\mathrm{i}}=\text { likelihood; } \\
& C_{\mathrm{i}}=\text { consequence }
\end{aligned}
$$


- Characteristics and estimation of the level of individual risk -using a simple matrix (see Tables 1 and 2) (Zvijáková [6]).

Table 1: Matrix of qualitative risk analysis.

\begin{tabular}{|c|c|c|c|c|c|}
\hline & \multicolumn{4}{|c|}{ Consequence } \\
\hline & & marginal & small & medium & large \\
\hline \multirow{4}{*}{ 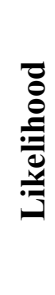 } & negligible & negligible & negligible & low & middle \\
\hline & unlikely & negligible & low & middle & high \\
\hline & likely & negligible & low & high & high \\
\hline & $\begin{array}{l}\text { highly } \\
\text { unlikely }\end{array}$ & low & middle & high & high \\
\hline
\end{tabular}

A similar approach used the semi-quantitative analytical tool (as shown in Table 2.)

Table 2: Matrix of semi-quantitative risk analysis.

\begin{tabular}{|c|c|c|c|c|c|}
\hline & \multicolumn{4}{|c|}{ Consequence } \\
\hline & & 0.25 & 0.50 & 0.75 & 1.00 \\
\hline \multirow{4}{*}{ 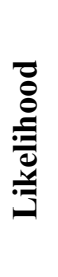 } & 0.25 & 0.0625 & 0.125 & 0.1875 & 0.25 \\
\hline & 0.50 & 0.125 & 0.25 & 0.375 & 0.50 \\
\hline & 0.75 & 0.1875 & 0.375 & 0.5625 & 0.75 \\
\hline & 1.00 & 0.25 & 0.50 & 0.75 & 1.00 \\
\hline
\end{tabular}

The calculated risk of each individual risk is then classified into one of the matrices of risk analysis and so the level of risk is estimated.

The objective of the risk matrix is to provide guidance to characterize the relationship between likelihoods and consequences of individual risks (Zvijáková [6]). Assessment of the likelihood and consequence are combined in order to set an individual risk of stressor to environmental components. The risk matrix is a tool to achieve a risk assessment of the proposed activity on the environment.

- Determination of risk index $I R_{\mathrm{j}}$ for each alternative of the proposed action - according to equation (2):

$$
I R_{j}=\sum_{i=1}^{n} L_{i} \cdot C_{i}
$$

where $\quad I R=$ risk index;

$L=$ likelihood; 
$C=$ consequence;

$j \quad=$ rank of the alternative;

$n=$ number of considered impacts of stressors to environmental components $(\mathrm{n}=1,2,3, \ldots, 70)$;

$i=$ rank of likelihood and consequences.

The next section presents the application of the proposed methodology of environmental impact assessment of the proposed activity from the field of water management - flood protection measures.

\section{Results}

The proposal of this procedure using RA for determining the risk of flood protection object and choosing the best alternative of the activity is applied for a flood protection object proposal in the village of Snakov (Fig. 2).

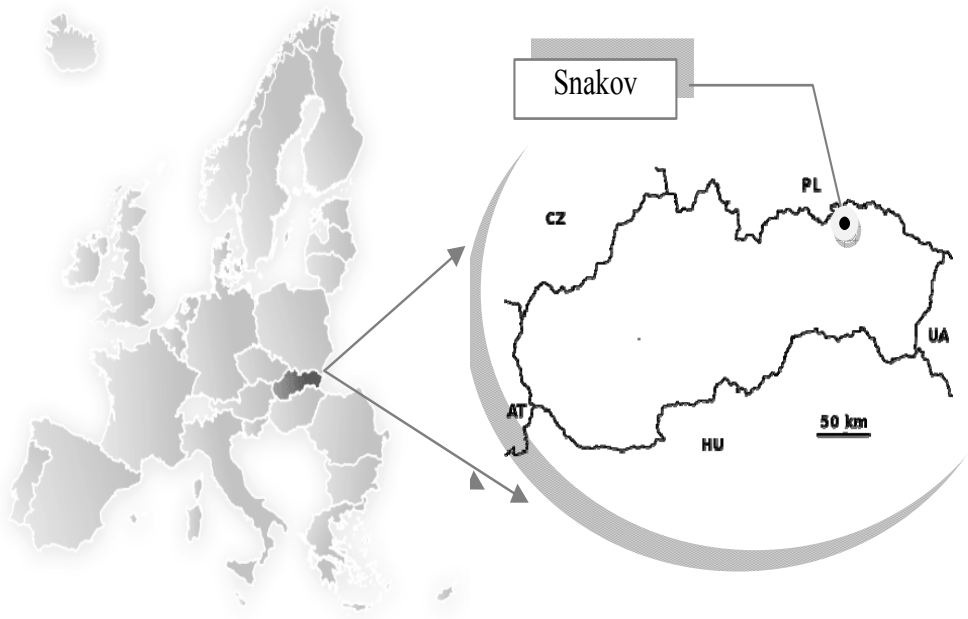

Figure 2: Location of Snakov village in the Slovak Republic.

Snakov is a village and municipality in Bardejov District in the Prešov Region of north-east Slovakia. It is located in the Ondavská highlands on Vesná stream. This stream is a constant threat of flooding in the village. It is therefore necessary to have drainage areas to give care and protection of the environment and people.

The purpose of the proposed action is to regulate runoff conditions in order to improve flood protection in the vicinity of the flow. The proposed alternatives for the proposed activity "flood protection object" in Snakov village are:

- Alternative 0: stream bed will not be regulated - the current state.

- Alternative I: stream bed will be regulated and the polder will be constructed above the village.

- Alternative II: stream bed in the village will be regulated for $Q_{100}$. 
Selection of the optimal alternative or ranking of the alternatives assessed in order of suitability

According to equation (2), the resulting risk indices are calculated. For Alternative $0, I R_{0}=15.00$; Alternative $\mathrm{I}$ has a value of $I R_{\mathrm{I}}=13.8125$ and Alternative II has $I R_{\mathrm{II}}=14.9375$.

Proposal of an optimal alternative is based on a comparison of the level of risk of the proposed activity on the environment, on the basis of which is the suitability of assessed alternatives is prioritized. Comparison of the risk indices $I R_{\mathrm{j}}$ of the assessed alternatives is graphically presented in Figure 3.

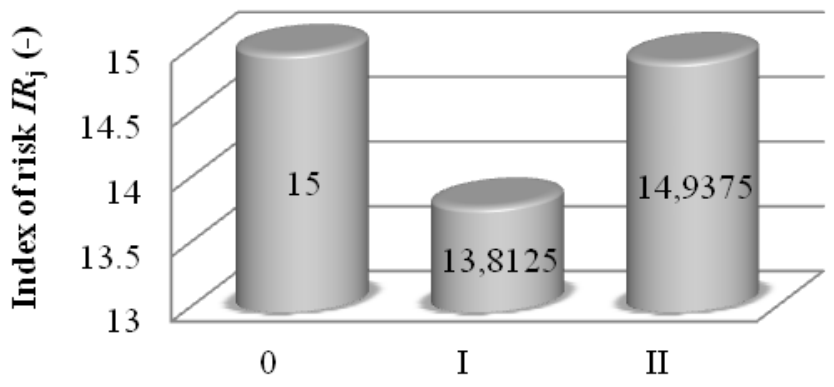

Alternative $\boldsymbol{A}_{\mathrm{i}}(-)$

Figure 3: Assessment of alternatives of flood protection facilities in Snakov village based on the risk index.

The first place presents an Alternative I that is optimal in terms of the degree of risk posed to the environment. The second place is Alternative II which is less acceptable and the third place is Alternative 0, which is the least acceptable and the most risky in terms of the level of risk to the environment.

Table 3: $\quad$ Final risk assessment.

\begin{tabular}{|c|c|c|}
\hline Risk index $I R_{\mathrm{j}}(-)$ & Category & $\begin{array}{c}\text { Degree of risk of the proposed activity on } \\
\text { the environment }\end{array}$ \\
\hline $4.375-15$ & $\mathrm{IV}^{\text {th }}$ & very low \\
\hline $15.01-25$ & $\mathrm{III}^{\mathrm{rd}}$ & low \\
\hline $25.01-40$ & $\mathrm{II}^{\text {nd }}$ & medium \\
\hline $40.1-70$ & $\mathrm{I}^{\text {st }}$ & high \\
\hline
\end{tabular}

The object of flood protection according to Table 3 is assigned to the $\mathrm{IV}^{\text {th }}$ category of water structure, which was designed based on the calculated risk index and presents a very low level of risk to the environment. 


\section{Conclusion}

Quantifying risk using risk indices such as the expected number of fatalities, gives an impression that risk can be expressed in a very precise way. However, in most cases, the arbitrariness is large, and the semi-quantitative approach acknowledges this by providing crude risk numbers, including assessments of the factors that can cause "surprises" relative to the probabilities and expected values.

We are not opposed to detailed risk quantification as such, but quantification often requires strong simplifications and assumptions and, as result, important factors could be ignored or given too little (or too much) weight. In a qualitative or semi-quantitative analysis, a more comprehensive risk picture can be established, taking into account the underlying factors influencing risks. In contrast to the prevailing use of quantitative risk assessments, the precision level of the risk description is in line with the accuracy of the risk assessment tool. In addition, risk quantification is very resource demanding.

We need to ask whether the resources are used in the best way. We conclude that in many cases, more is gained by pursuing a broader more qualitative approach, which allows for considerations beyond the probabilities and expected values.

For problems with large uncertainties, risk assessments could support decision making, but other principles, measures and instruments are required, such as the cautionary principle (Aven [2]).

On the basis of this assessment we may justify the proposal as follows. A comparison of alternatives for the proposed action - flood protection facilities in Kružlov village at Slatvinec stream, all three considered alternatives (Alternative 0, Alternative I and Alternative II) are presented on the basis of the calculated risk index $I R_{\mathrm{j}}$ various categories $\left(\mathrm{IV}^{\mathrm{th}}\right.$ or $\left.\mathrm{III}^{\mathrm{rd}}\right)$ of environmental risk. Based on the risk index $I R_{\mathrm{j}}$ we can state that Alternative $\mathrm{I}$ is optimal, in light of expected environmental impacts, and therefore it is recommended to regulate the Vesná watercourse in Snakov village and build the polder above the village.

\section{Acknowledgement}

The contribution is written thanks to the support of project VEGA 1/0609/14.

\section{References}

[1] Act of Law No. 24/2006 from December 14th 2005 on Environmental Impact Assessment and on amendments to certain acts.

[2] Aven, T.: Risk analysis and management. Basic concepts and principles. R\&RATA 1(12): 2, 2009.

[3] Boroush, M.: Understanding risk analysis: a short guide for health, safety, and environmental policy making. Internet ed. Washington, DC: American Chemical Society and Resources for the Future, 40 p., 1998. http://www.rff.org/rff/publications/upload/14418 1.pdf 
[4] Startienè, G., Remeikienè R.: Methodology of business risk analysis and its practical application in the enterprises working in the global market. Engineering Economics. 3: 1-15, 2007.

[5] Aven, T., Vinnem, J. E., Røed W.: On the use of goals, quantitative criteria and requirements in safety management. Risk Management: an International Journal. 8: 118-132, 2006.

[6] Zvijáková, L.: The application of risk analysis in the environmental impact assessment (selected constructions) (in Slovak). Dissertation work. Košice: TUKE, SvF, 2013.

[7] Karelová, Z., Vranayová, Z., Káposztásová, D., Purcz, P.: Risk analysis for RWH system and its verification by mathematical methods. In: Visnik Nacional'nogo universitetu L'vivska politechnika: teorija $i$ praktika budivnictva. 756: 74-77, 2013.

[8] Gałaś, S., Gałaś, A.: Assessment of ecological stability of spatial and functional structure around Świnna Poręba water reservoir. Polish Journal of Environmental Studies; 18(3A): 83-87, 2009.

[9] Gałaś, S., Zeleňáková, M., Slezingr, M.: Environmental risk assessment in river catchments. Polish Journal of Environmental Studies; 20(4A): 72$75,2011$.

[10] Zeleňáková, M., Zvijáková, L.: The Implementation of Environmental Impact Assessment Process in Visegrad Group Countries. Ed. Šauer, P. et al. In: Visegrad Countries: Environmental Problems and Policies, Praha: Cenia, 203-215, 2013. 